\title{
Parameters estimation of solar photovoltaic module using camel behavior search algorithm
}

\author{
Kadhim H. Hassan', Abdulmuttalib T. Rashid ${ }^{2}$, Basil H. Jasim ${ }^{3}$ \\ ${ }^{1}$ Basrah Engineering Technical College, Southern Technical University, Iraq \\ ${ }^{2,3}$ College of Engineering, University of Basra, Iraq
}

\begin{tabular}{l} 
Article Info \\
\hline Article history: \\
Received Apr 12, 2020 \\
Revised Jul 11, 2020 \\
Accepted Jul 27, 2020 \\
\hline
\end{tabular}

Keywords:

Camel behavior search

algorithm

Parameter estimation

Photovoltaic (PV) model

\begin{abstract}
Finding accurate mathematical model of electrical equivalent circuit of solar photovoltaic (PV) cell is crucial to achieve and improve maximum power point, simulation design and efficiency computations for solar energy system. Due to the nonlinearity of the characteristic of solar PV cell, optimization methods are the best for estimating the electrical model parameters which lead to accurate estimating I-V curve. In this paper, camel behavior search algorithm is proposed as a new method for estimating the five different parameters for single diode model of PV solar module. This is tested on multicrystalline KC 200GT PV module. A measurement data of the module is used to verify and test the consistency of accurately estimating the set of parameters that govern the characteristics I-V relationship of solar cell. The simulation results show that the current-voltage characteristic and power-voltage curve obtained are matching to the measured experimental data set. For performance evaluation, the proposed method is simple, fast in convergence response and has an acceptable accuracy in obtaining the five estimated parameters.
\end{abstract}

\section{Corresponding Author:}

Kadhim H. Hassan,

Department of Automation and Control,

Basrah Engineering Technical College,

Southern Technical University, Iraq.

Email: k.hassan@stu.edu.iq

\section{INTRODUCTION}

Today, due to the increasing attention of the renewable energy sources to tackle the problems of fossil fuels, the application of solar energy is increasing constantly worldwide to constitute one of the most promising energy source in the future [1-4]. The expectation of global solar capacity will be more than 160 GW by 2021 [5]. PV power generators are not only able to converting sunlight into electricity but can do so without pollution, no much noise, simple and short installation $[6,7]$.

Precise modelling of photovoltaic solar cell is critical for control, simulation and optimization of PV systems. It is also critical for efficient design of maximum power point tracking [8, 9]. Therefor the preliminary step for improving the performance and effectiveness of solar system is the design procedure of modeling the PV module. The mathematical model of $\mathrm{I}-\mathrm{V}$ characteristic is used for simulation of PV module. However, PV modelling is complicated design problem due to nonlinear nature of I-V characteristic curve [10-13].

Some parameters of PV module are listed in the data-sheet by the manufacturer such as open circuit voltage, short circuit current, maximum voltage-current point and maximum power. When designers focus on 
these parameters, we can find multiple current- voltage characteristics, although a solar cell in reality has a unique I-V curve $[14,15]$ So, the PV module model needs other parameters such as photo current $\left(I_{p h}\right)$, saturated current $\left(I_{o}\right)$, series resistance $\left(R_{S}\right)$, shunt resistors $\left(R_{s h}\right)$ and diode identity factor $(a)$. As these parameters are not listed in the datasheet. The identifying of accurate values of such parameters is essential task [16]. Accurate model parameters should lead to characteristic curve as close as possible to the measurement data or information available in manufactural datasheet. Since the (I-V) characteristic of solar cell is nonlinear, the estimation problem of PV cell parameters is considered as a nonlinear optimization problem [17].

Different approaches have been applied in the literature for PV parameter estimation. All these techniques can be categorized in three main methodologies: Analytical methods, Numerical extraction and Meta- heuristic algorithms. Analytic techniques used the available information in data-sheet or current-voltage characteristic curve point to solve the mathematical equations of the equivalent circuit parameters [18-20]. Numerical extraction methods are based on curve fitting by using some information in the manufacturer data-sheet. However, curve fitting of nonlinear PV characteristic suffers from complexity in mathematical derivation, need initial conditions and required certain assumptions [21]

Meta- heuristic optimization algorithms including (evolutionary algorithms, swarm based algorithms and physical based algorithms) have attracted much attention in recent research to deal with high nonlinear and nonconvex problems without involving excessive arithmetic computations in order to give better accuracy and reliability [22]. These approaches are populistic and population based and inspired from nature that efficient in solving engineering optimization problems. Various optimization approaches have been applied in the recent past. In these algorithms the estimation problem is converted into optimization problem, these including genetic algorithm [23, 24], particle swarm optimization [25, 26], wolf optimization [27], differential evolution [28] and artificial bee colony [29] as well as other types of optimization.

Among all these proposed algorithms, no proficient in terms of the robustness, accuracy and speed with respect to other methds. In this paper, we present the use of a new search algorithm based on the camel travelling behavior in desert. As a result, the proposed method shows good performance in terms of accuracy in estimation process and less computation time.

\section{PV PARAMETERS ESTIMATION PROCESS}

The modelling and design of solar PV module is important to enable the PV system to predict the (I-V) characteristics and to analyze the effect of different factors on the performance of the module under different operation conditions [30]. In our work, the single diode model is used, which is often described as the most popular and widely used model [24].

\subsection{Single diode model}

The equivalent circuit of a PV solar cell represented by single diode is shown in Figure 1. The electrical circuit model is composed of a photo current source in parallel connected with a single diode and two resistances; the shunt resistance is provided to simulate the leakage current across the semiconductor junction where the series resistance represents the metal-omic contact with the semiconductor [30].

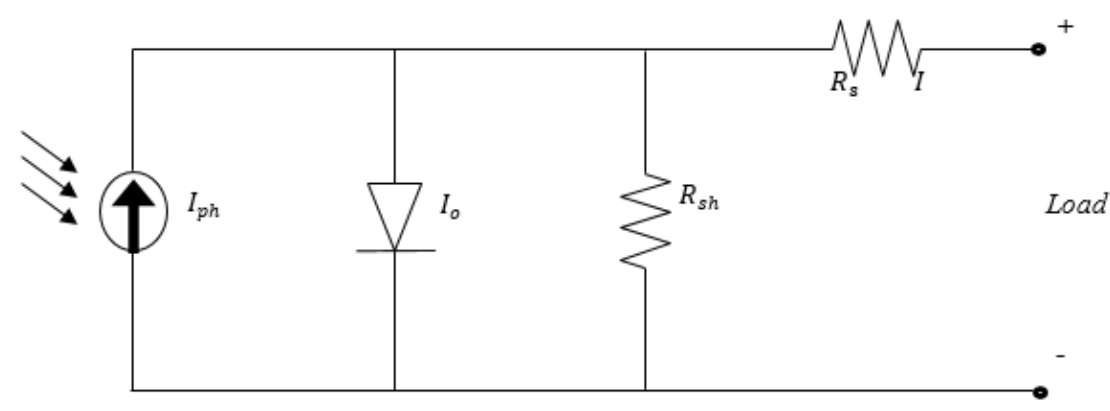

Figure 1. The electrical circuit model

To determine the current-voltage relation, apply Kirchhoff's law, given by:

$$
I=I_{p h}-I_{D}-I_{s h}
$$


where:

$I_{D}:$ the diode current which induces the nonlinearity of a solar cell

$I_{s h}$ : the current following through the shunt resistance.

Hence the output current can be written in the following final expression:

$$
I=I_{p h-} I_{o}\left(e^{\frac{V+I R_{S}}{a V_{t}}}-1\right)-\frac{V+I R_{S}}{R_{s h}}
$$

where:

$I_{o}$ : the revers saturation current

$a$ : the ideality factor

$v_{t}:$ is the thermal voltage $=K T / q$.

$\mathrm{K}:$ Boltzmann constant $=1.38 \times 10^{-23} \mathrm{~J} / \mathrm{K}$.

$\mathrm{T}$ : temperature in kelven

$\mathrm{q}$ : the electron charge $=1.602 \times 10^{-19} \mathrm{C}$.

\subsection{Parameters estimation as optimization problem}

The objective of modelling solar cell consists in accurately estimating the five parameters in (2), defined by vector $x=\left[I_{p h} I_{o} R_{s} R_{s h} a\right]$ to convert the parameter set estimation problem into optimization problem, experimental (I-V) data are commonly obtained and used to minimize the deference between measured and calculated (I-V) curve data. That it is looking for set of parameters that produces the best approximation to the (I-V) curve obtained by the true PV solar cell. Therefor it is important to introduce a fitness function that assess the matching between the identified parameters and the experimental data. In this work, root mean square error is selected as the fitness function to evaluate the difference between the PV model output and experimental data as defined by the following formula:

$$
F(x)=\operatorname{RMSE}(x)=\sqrt{\frac{1}{N}(f(V, I, x))^{2}}
$$

where:

$x$ : Unknown parameter vector,

$$
x=\left[I_{p h} I_{o} R_{s} R_{s h} a\right]
$$

$N$ : Number of experimental data

$$
f(V, I, x)=x_{1-} x_{2}\left(e^{\frac{V+I x_{3}}{x_{5} V t}}-1\right)-\frac{V+I x_{3}}{x_{4}}-I
$$

\section{CAMEL SEARCH BEHAVIOR ALGORITHM}

The camel search behavior is a new optimization method that mimics the behavior of travelling camels over desert for foraging site process [31]. The camels can adapt themselves to resist for long time with shortage of water and food and able to withstand extreme circumstances and fallow their nature behavior in finding food. First the camels are spreading out over the searching region. Once a site of abundant food is reached from one camel a communication with other camels to attract them to the site, once the caravan members find out the position of the camel at which they modify the searching path towards the new position. The food position may not be visible to all camels due to dunes in the desert, in such a case wake away from sight continue in random movement to lock for another food position. Through the searching process, another best food site can be found by another camel [31]. The modification of camel's rout continues until reaching the best position. In implementation there are $N$ camel caravans travelling through $D$ dimension. The camel location can be defied as vector $x^{i, i t r}=\left[x_{1}^{i, i t r}, x_{2}^{i, i t r}, x_{3}^{i, i t r}, \ldots . x_{D}^{i, i t r}\right]$ where $i=1,2,3, \ldots N$ and $i t r=1,2,3, \ldots i t r_{\max }$ the random spreading out of the camels is expressed in the following formula:

$$
x_{d}^{i, i t r}=\left(x_{\max }-x_{\min }\right) \text { Rand }+x_{\min }
$$


where $d=1,2,3, \ldots D$, Rand represents a uniformly distributed random number between $(0$ to 1$)$, $x_{\min }$ refers to the camel minimum limit and $x_{\max }$ is the camel location maximum limit. A fitness function is introduced to location evaluate the best location. The amount of environmental temperature $T$ influences the camel movement. Since different camels are moving towards scattered locations, they meet different levels of temperature resulting in different grades of endurance. The influence of temperature $T$ of camel $i$ at iteration $i t r$ is given by:

$$
T_{d}^{i, i t r}=\left(T_{\max }-T_{\min }\right) \text { Rand }+T_{\min }
$$

The formula of the endurance $E$ of each camel in respect to the temperature is given below:

$$
E_{d}^{i, i t r}=1-\frac{\left(T_{d}^{i, i t r}-T_{\min }\right)}{\left(T_{\max }-T_{\min }\right)}
$$

The update equation of Camel behavior algorithm is given by:

$$
x_{d}^{i, i t r}=x_{d}^{i, i t r-1} E_{d}^{i, i t r}\left(x_{d}^{b e s t}-x_{d}^{i, i t r-1}\right)
$$

where $x_{d}^{b e s t}$ is the global best position which represents the PV estimated parameters vector. When the visibility is less than a specific threshold, the update of location returns to follow (6).

\section{EXPRIMENTS AND RESULTS}

In order to test and evaluate the camel search algorithm in estimating process of the PV cell parameters, a case study is designed to use a commercial KC200GT multi- crystal PV module [32]. During the estimation process, the analysis is applied to minimize the objective function $f(V, I, x)$ to evaluate the quality of fitted model to the experimental data set. The experimental data of the KC200GT module has been taken from [33]. As mentioned earlier the extracted parameters are used to predict the I-V characteristics for designing process. Figure 2 shows the I-V curve using the estimated set of parameters in comparison to simulated values of the presented PV module. The power vs. voltage $(\mathrm{P}-\mathrm{V})$ characteristics of the simulation and experiments data of the system is also shown in Figure 3.

The optimal values of estimated parameters are listed in Table 1 for single diode module of the KC200GT module using the presented camel search algorithm. The convergence curve of the proposed method is iiiustrated in Figure 4. It can be seen from Figure 2 and Figure 3, that the characteristic curves exhibit a well predicted performance which indicates that camel search method is capable of extracting all the five parameters of single diode model. In comparision with particle swarm optimization, the camel search algorithm is simpler, faster in the early stages of convergence and it proposed good results in terms of accuracy.

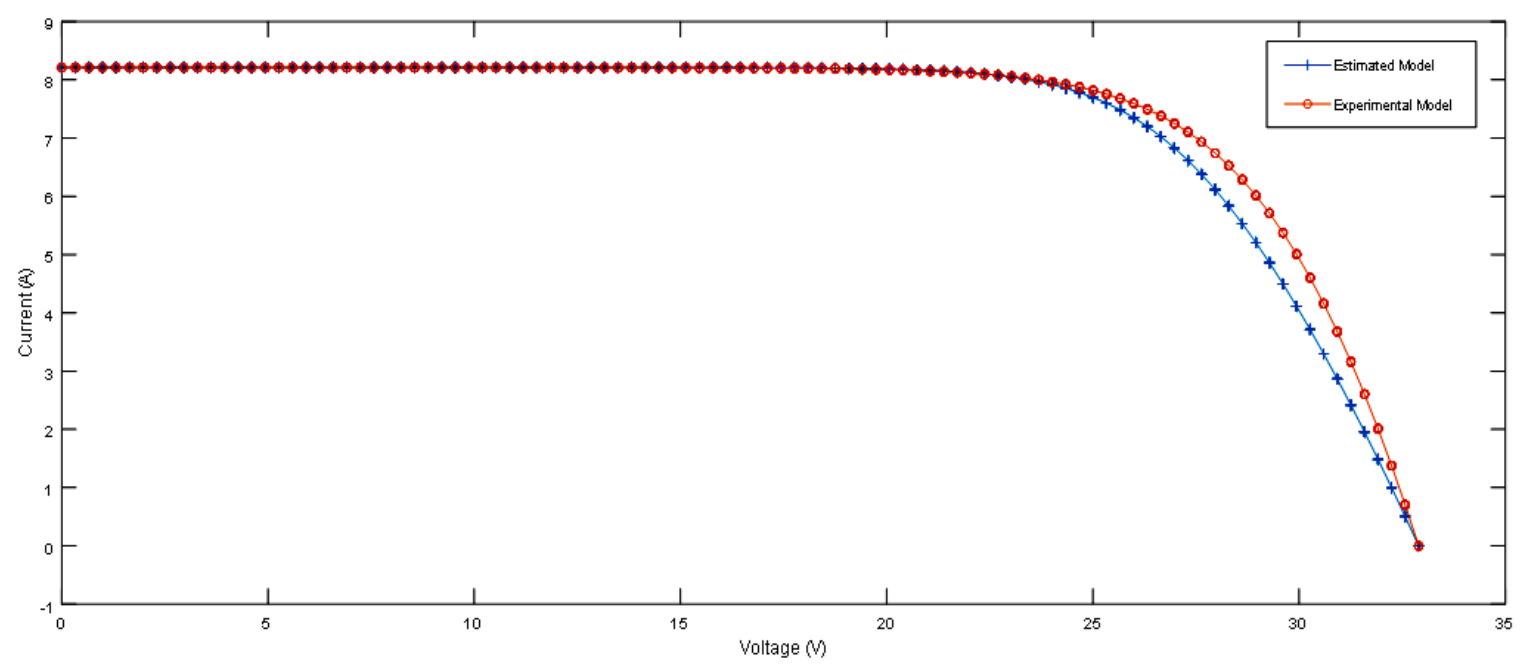

Figure 2. Comparison between I-V characteristics obtained from the experimental of the single diode model 


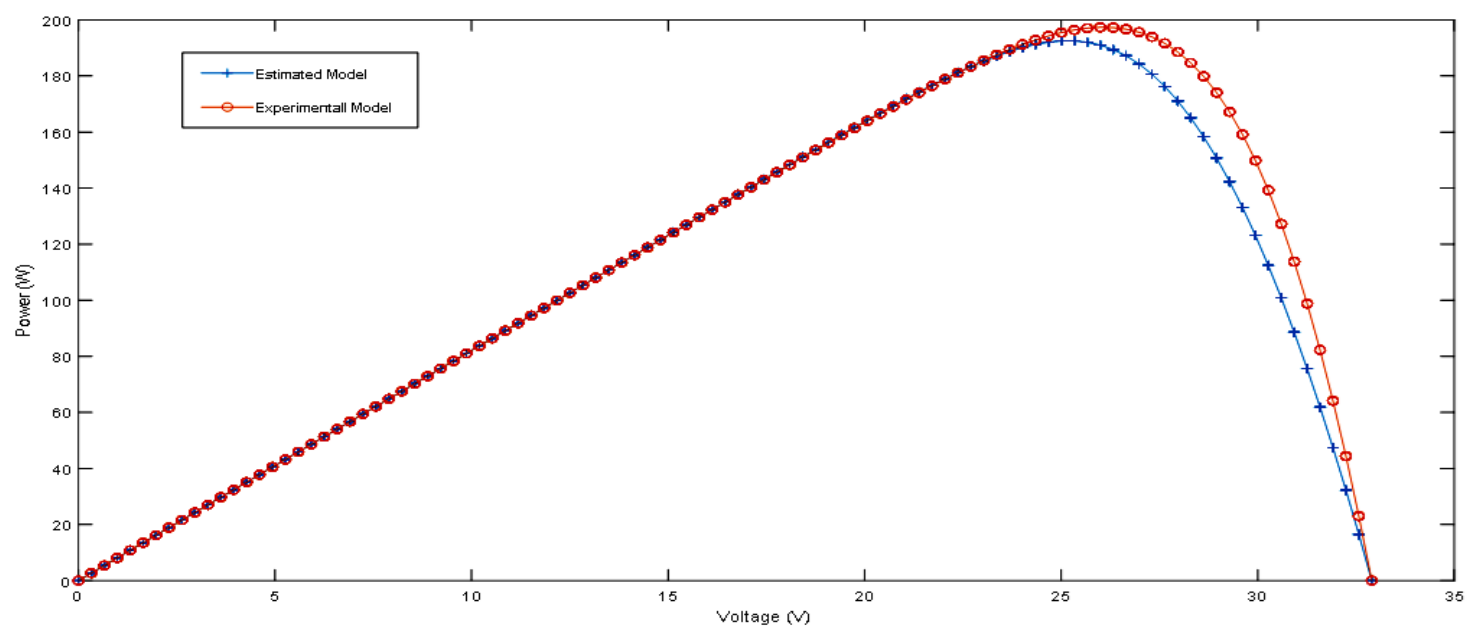

Figure 3. Comparison between the P-V curves resulted from the experimental data of the single diode model

Table 1. Estimated single diode parameters of the KC200GT module

\begin{tabular}{lcccrc}
\hline Parameter & $\boldsymbol{I}_{\boldsymbol{p h}}$ & $\boldsymbol{I}_{\boldsymbol{O}}$ & $\boldsymbol{R}_{\boldsymbol{s}}$ & $\boldsymbol{R}_{\boldsymbol{s} \boldsymbol{h}}$ & $\boldsymbol{a}$ \\
\hline Value & $8.181 \mathrm{~A}$ & $8.721 \times 10^{-8} \mathrm{~A}$ & $0.215 \Omega$ & $332.6 \Omega$ & 1.28 \\
\hline
\end{tabular}

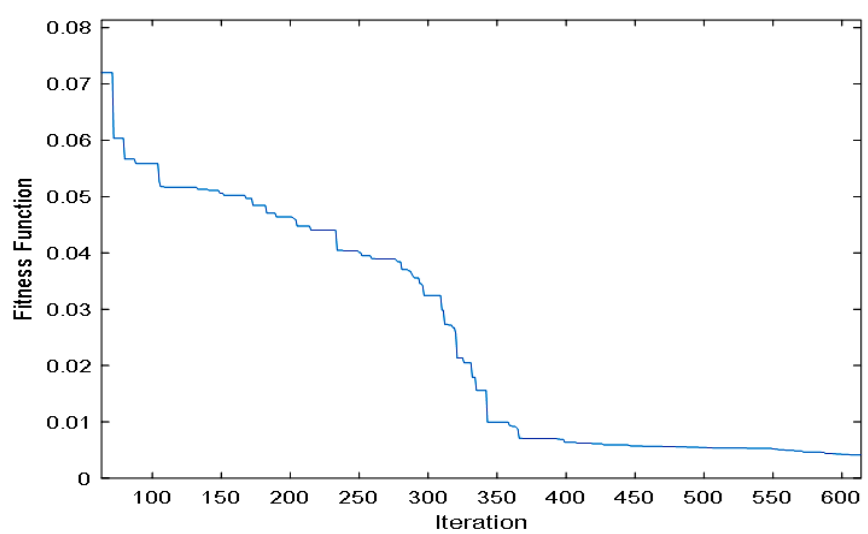

Figure 4. The convergence curve

\section{CONCLUSION}

In this work, a new optimization technique has been implemented, called camel behavior algorithm to identify the unknown parameter set of KC200GT solar module for single diode model to obtain the PV model that serves in wide functions of design and simulation. The proposed method was evaluated through prediction of $\mathrm{I}-\mathrm{V}$ and $\mathrm{P}-\mathrm{V}$ characteristics by using the optimal estimated values of the five different parameters. It is worth to know that the simulation results of the camel search based solar PV model fit the contemplated results and that the new presented model can be trusted to design PV solar systems.

\section{REFERENCES}

[1] Tan, J. D., et al., "An electromagnetism-like mechanism algorithm approach for photovoltaic system optimization," Indonesian Journal of Electrical Engineering and Computer Science (IJEECS), vol. 12, no. 1, pp. 333-340, 2018.

[2] Nazri, N. S., et al., "Mathematical modeling of photovoltaic thermal-thermoelectric (PVT-TE) aircollector," International Journal of Power Electronics and Drive Systems (IJPEDS), vol. 9, no. 2, pp. 795-802, 2018.

[3] M. Calacan, et al., "Estimation of Single-Diode and Two-Diode Solar Cell Parameters by Using a Chaotic OptimizationApproach," Energies, vol. 12, no. 21, 2019. 
[4] H. Chen, et al., "Parameters Identification of Photovoltaic Cells and Modules Using Diversification-enriched Harris Hawks Optimization with Chaotic Drifts," Journal of Cleaner Production., vol. 244, 2019.

[5] C. Keethisinghe, et al., "PV and Demand models for a Markov Decision Process Formulation of the Home Energy Management Problem," IEEE Transactions on Industrial Electronics, vol. 66, no. 2, pp. 1424-1433, 2019.

[6] H. M. Hasanien, Ahmed Al-Durra, and S. M. Muyeen., "Gravitation Search Algorithm-Based Photovoltaic Array Reconfiguration for Partial Shading Losses Reduction," IET Renewable Power Generation Conf., 2016.

[7] A. M. Humada, et al., "Solar Cell Parameters Extraction Based on Single and Double Diode Models: A Review," Renew. Sustain. Energy Rev., vol. 56, pp. 494-509, 2016.

[8] D. Oliva, et al., "A Review on Meta-Heuristics Methods for Estimating Parameters of Solar Cells," Journals of Power Sources, vol. 435, 2019.

[9] M. Abdulkareem and M. Saravana, "A Simple and Accurate Parameter Identification Technique for Two Diode Six Parameter Photovoltaic Model," Australian journal of basic and applied sciences, vol. 8, no. 13, pp. 171-179, 2014.

[10] D. Mathew, et al., "Wind Driven Optimization Technique for Estimation of Solar Photovoltaic Parameters," IEEE J. Photovolt., vol. 8, no. 1, pp. 248-256, 2017.

[11] M.H. Qais, et al., "Coyote Optimization Algorithm for Parameters Extraction of Three Diode Photovoltaic Model of Photovoltaic Modules," Energy, vol. 187, pp. 1-8, 2019.

[12] M. H. Qais et al., "Identification of Electrical Parameters for Three diode Photovoltaic Model Using Analytical and Sunflower Optimization Algorithm,” Appl. Energy, vol. 250, pp. 109-117, 2019.

[13] G. Xong, et al., "Parameter Estimation of Solar Photovoltaic Models by Means of a Hybrid Differential Evaluation with Whale Optimization Algorithm," Solar Energy, vol. 176, pp. 109-117, 2018.

[14] M. Calacan, et al., "Estimation of Single-Diode and Two-Diode Solar Cell Parameters by Using a Chaotic Optimization Approach," Energies, vol. 12, pp. 1-15, 2019.

[15] Q. B. Mirza, Hassan Abbas Khan, and Syed Muhammad Ahsan.," Evaluation of Solar Module Equivalent Models Under Real Operation Conditions-A Review," Journal of Renewable and Sustainable Energy, vol. 21, no. 1, 2020.

[16] A. Fathy and H. Rezk "Parameter Estimation of Photovoltaic System Using Imperialist Competitive Algorithm," Renewable Energy, vol. 111, pp. 307-320, 2017.

[17] M. Derick, et al., "An Improved Technique for Estimation Solar Photovoltaic Parameters,” Solar Energy, vol. 152, pp. 116-124, 2017.

[18] A. R Jordehi "Parameter Estimation of Solar Photovoltaic (PV) Cells: A Review," Renewable and Sustainable Energy Reviews, vol. 61, pp. 354-371, 2016.

[19] Mohapatra, A., et el., "Parameter Extraction of PV Module using NLS Algorithm with Experimental Validation," International Journal of Electrical and Computer Engineering (IJECE), vol. 7, no. 5, 2017.

[20] I. Nasser-eldin, et al, "Parameter Estimation of Photovoltaic Modules Using Iterative Method and the Lambert W Function: A Comparative Study," Energy Conver.And Manage., vol. 119, pp. 37-48, 2016.

[21] Q. Niu, L. Zhang and K. Li, "A Biogeography-Based Algorithm with Mutation Strategies for Model Parameter Estimation of Solar and Fuel Cells," Energy Conver. And Manage., vol. 86, pp. 1173-1185, 2014.

[22] U. Jadli, P. Thakur and R. D. Shukla., "A New Parameter Estimation Method of Solar Photovoltaic," IEEE Journal of Photovoltaic, vol. 8, no. 1, pp. 239-247, 2018.

[23] A. M. Dzqah, et al., "An Accurate Method for the PV Model Identification Based on Genetic Algorithm and the Interior-Point Method," Renew. Energy, vol. 12, vol. 72, pp. 212-222, 2014.

[24] B. Rodriguez, et al.," A Genetic Algorithm for Identification the Single Diode Model Parameters of a Photovoltaic Panel," Math. Comp. Sim., vol. 131, pp. 38-54, 2017.

[25] S. Ebrahimi, et al., "Parameter Identification of PV Solar Cells and Modules Using Flexible Particle Swarm Optimization Algorithm," Energy, vol. 179, pp. 358-372, 2019.

[26] M. Ye, X. Wang, and Y. Xu, "Parameter extraction of solar cells using particle swarm optimization," J. Appl. Phys., vol. 105, no. 9, pp. 1-9, 2009.

[27] Tumari, M. M., Suid, M. H. and Ahmad, M. A., "A modified Grey Wolf Optimizer for improving wind plant energy production,” Indonesian J. of Electr. Engineer. and Comp. Sci., vol. 18, no. 3, pp. 1123-1129, 2020.

[28] L. L. Jiang, D. L. Maskell, and J. C. Patra, "Parameter Estimation of Solar Cells and Modules Using an Improved Adaptive Differential Evolution Algorithm," Appl. Energy, vol. 112, pp. 185-193, 2013.

[29] Oliva, D., Cuevas, Erik and Pajares, Gonzalo, "Parameter Identification of Solar Cells Using Artificial Bee Colony Optimization," Energy, vol. 72, pp. 93-102, 2014.

[30] I. Nassar-Eddine, et al., "Parameters estimation of the single and double diode photovoltaic models using a gauss-seidel algorithm and analytical method: A comparative study," Energy Conversion and Manag., vol. 148, pp. 1041-1054 2017.

[31] R. S. Ali, F. M. Alnahwi and A. S. Abdullah., "A Modified Camel Traveling Behavior Algorithm for Engineering Applications," Australian Journal of Electrical and Electronics Engineering, pp. 1-11, 2019.

[32] "KC200GT High Efficiency Multicrystalline Photovoltaic Module Datasheet Kyocera," [Online]. Available: http://www.kyocera.com.

[33] Jieming M., "Optimization Approaches for Parameter Estimation and Maximum Power Point Tracking (MPPT) of Photovoltaic Systems," PhD Thesis, Liverpool University, 2014 